\title{
Investigation of Waste Properties of Subway Construction as a Potential Component of Soil Layer
}

\author{
Andrey Vladimirovich Ivanov ${ }^{1 *}$, Yuri Dmitrievich Smirnov ${ }^{1}$, Georgiy Igorevich Petrov ${ }^{1}$ \\ 1 Saint Petersburg Mining University, 21st Line of Vasilyevsky Island, 2, Saint-Petersburg, 199106, Russia \\ *Corresponding author's e-mail: andrey-racer@mail.ru
}

\begin{abstract}
The construction of subway stations is inevitably accompanied by the formation of a large amount of waste that is extracted from the underground workings by rock. When the waste is transported, the air is polluted with the exhaust gases of the dump trucks, some of the waste can stay on the road surface, the use of dump trucks increases the load on the roadway, the disposal of waste at landfills harms the environment, and enterprises pay fees for the transportation as well as placement of the waste. The article deals with the waste from the construction of new stations in the Saint-Petersburg subway. In order to determine the possibility of using waste in the municipal economy, a comprehensive analysis of this waste was carried out, including determination of moisture content, acidity, total carbon content, as well as chemical and granulometric composition. On the basis of the study results, it was established that the waste in question belongs to the hazard class 5, which enables to use it as a component of the soil mixture. Afterwards, the hazard class 5 was confirmed by the method of bioassay based on the determination of water toxicity by changing the optical density of the Chlorella algae culture.
\end{abstract}

Keywords: subway, waste, soil, landfill, mine site, hazard class, total carbon, moisture, biotesting, Chlorella algae

\section{INTRODUCTION}

The subway of Saint-Petersburg ranks 4 th in Europe and 19th in the world in terms of the total annual passenger traffic and is the deepest in the world in terms of the average depth of the stations. Currently in Saint-Petersburg, as in other major cities in Russia and Europe, there an active construction of new subway stations is underway. The article deals with the construction of the Nevsko-Vasileostrovskaya line of the SaintPetersburg subway, namely the section from the station Primorskaya to the station Savushkina Street, including the station Novokrestovskaya-1. In the period of construction of subway stations, the inevitable generation of waste, the amount of which depends on the volume of building materials and seized masses of rock.

The resulting waste (rock) is stored on landfills. The landfills are located at a relatively large distance from the waste generation areas; the haulage of trucks is greater than $50 \mathrm{~km}$.
The applied waste management system causes certain problems:

- Environmental damage is caused by the location of waste dumps on lands in the vicinity of Saint-Petersburg [Pashkevich, 2015, Danilov et. al., 2017];

- the company pays a fee for storage of waste;

- the question arises of the high cost of transporting waste from the construction site;

- As a result of the organization of long distances of dump trucks, additional exhaust gases are emitted into the atmosphere, such as carbon monoxide $(\mathrm{CO})$, carbon dioxide $\left(\mathrm{CO}_{2}\right)$, nitrogen oxides $\left(\mathrm{NO}_{\mathrm{x}}\right)$, hydrocarbons $\left(\mathrm{C}_{\mathrm{x}} \mathrm{H}_{\mathrm{y}}\right)$, benzapyrene, soot, etc.;

- Part of the waste from loaded dump trucks falls to the roadway;

- There is an additional load on the roadway;

- traffic congestion of roads increases, the situation with traffic congestion is aggravated. 
On the territory of Saint-Petersburg, there is no disposal of the waste being studied. In this regard, there is a need to study the properties pertaining to the waste construction of subway stations to determine the possibility of their use in the urban economy.

\section{MATERIALS AND METHODS}

The sampling of waste and their laboratory storage is in accordance with the state methodical recommendations [PND F 12.1:2:2.2:2.3:3.2-03].

The study of the physical properties of waste includes:

1. Thermogravimetric method of moisture analysis. The measurement of moisture content in the soil under study is necessary to take into account the moisture content of the samples for some of the analysis methods discussed below;

2. Ion metric method of $\mathrm{pH}$ determination. The values of the hydrogen index should be taken into account when selecting the composition of the soil mixture;

3. Determination of the granulometric composition by the method of laser radiation diffraction. It is carried out in order to determine the mass fraction of each fraction (clay, sand, dusty particles), according to which it will be possible to accurately classify the waste being studied.

The definition of the elemental chemical composition includes:

1. Determination of the total carbon (TC) content by the high-temperature oxidation method. The values of TC must be taken into account while determining the elemental composition of the waste;

2. Determination of the elemental composition of waste by the wave X-ray fluorescence spectrometry method. The knowledge of the elementary composition will allow the calculation of the hazard class.

Definition of hazard class included:

1. Calculation of the hazard class of waste in accordance with the technique of classifying hazardous wastes as hazard classes for the environment [Methodical manual... 2003];

2. Confirmation of the hazard class in accordance with the methodology for determining the toxicity of water by changing the optical density of the chlorella algae [PND F T 14.1:2:3:4.10-2004].
The study was conducted on the basis of the Center for the collective use of high-tech equipment of the Saint-Petersburg Mining University.

The measurements were carried out using the AND MX-50 moisture meter. The moisture determination method corresponds to [GOST 5180-84].

The measurement was performed using an automatic potentiometric ATP-02 titrator with a special attachment in accordance with [GOST 26423-85].

Determination of the total carbon content was performed using a Shimadzu TOC device using the SSM-5000A solid sample analysis attachment in accordance with [GOST R 54244-2010 (ISO 29541: 2010)].

The chemical composition of the samples was studied using a XRF-1800 Shimadzu wave X-ray fluorescence spectrometer.

The analysis of the particle size distribution was carried out by laser diffraction using a laser particle size analyzer LA-950V2 Horiba in accordance with [ISO 13320-1].

The calculation of the hazard class was carried out in accordance with the current methodical manual [Order of the Ministry... 2014]. After collecting all the necessary information, the calculation was carried out in the "Integral. Calculation of hazard class 4.0" program. The software fully implements the algorithm for calculating the hazard class of waste, prescribed in the order of the Ministry of Natural Resources and Ecology of the Russian Federation of December 4, 2014 \# 536.

In order to determine the toxicity of waste, a methodology was used to identify the toxicity of water from the change in the optical density of the Chlorella algae [PND F T 14.1:2:3:4.10-2004]. Light exposure of samples was made in a KVM05 multi-cultivator.

\section{RESULTS AND DISCUSSION}

The waste (rock) formed during excavation works is mostly clay (up to $50 \%$ ), loam (up to $30 \%$ ), and also sands (up to $20 \%$ ). While choosing the method of utilization, special attention is paid to the properties of clays and studies the ways of their possible use. There are many directions for the use of clay, such as: the production of building materials, refractory materials, ceramic products, the production of drilling fluids, use as a sorbent, and also the production of soil [Chukhrov et al., 1970]. 
On the territory of Saint-Petersburg and the Leningrad region, there are areas for which the improvement works are required. As a rule, while carrying out such measures, the soil corresponding to the sanitary norms [SanPiN 2.1.7.1287-03], i.e. requirements for vegetative soil, ensuring optimal growth and healthy state of green plantations and being economically and logistically accessible, is necessary.

The secondary use of waste in close proximity to the places of their formation partially solves the problems associated with long hauling distances dump trucks to storage sites.

The main waste-generating production processes are connected with excavation. Excavation works include: development of soil for shafts and near-barreled workings, inclined (escalator) tunnels, stations with substation facilities, dead ends, exit chambers, distillation tunnels and dormitories, vestibules, upper ventilation units, built open and closed. The volumes of soil formed during these works for all 5 years of construction are given in Table 1.

In the work, waste is considered as a potential component of the soil mixture, which can be used to solve the problems arising in the city and the immediate area, such as:

- creation of a soil-vegetative layer (SVL) in the territories disturbed by construction;

- restoration of SVL on disturbed and polluted landscapes;

- increase in the power of the SVL, for example, in low-lying, flooded zones;

- subsidence of soil during the reorganization of the SVL;

- creation of SVL in alluvial landscapes;

- Reclamation of the disturbed and polluted areas of Saint-Petersburg and the region, for example, waste landfills.
Of course, any application of waste to create a soil-vegetation layer requires a preliminary study on the properties of this waste, on the basis of which the following tasks are formulated:

1. studying the physical properties of waste;

2. determination of the elemental chemical composition;

3. establishment of a hazard class and toxicity.

The mineral composition of the waste in question is mainly clay, fine-grained rock, consisting of particles smaller than $0.01 \mathrm{~mm}$ and containing about $30 \%$ of particles smaller than $0.002 \mathrm{~mm}$. The material composition includes: clay minerals (kaolinite, montmorillonite, hydromica), quartz, mica, oxides and hydroxides of iron, aluminum, carbonates, sulfates, phosphates, organic matter.

Clay minerals are water aluminosilicates $\left(\mathrm{xAl}_{2} \mathrm{O}_{3} \cdot \mathrm{ySiO}_{2} \cdot \mathrm{zH}_{2} \mathrm{O}\right)$, where $\mathrm{x}, \mathrm{y}$, $\mathrm{z}$ have different values. Other secondary minerals include quartz $\left(\mathrm{SiO}_{2}\right)$, gypsum $\left(\mathrm{CaSO}_{4} \cdot 2 \mathrm{H}_{2} \mathrm{O}\right)$, dolomite $\left(\mathrm{MgO} \cdot \mathrm{CaO} \cdot \mathrm{CO}_{2}\right)$, glauconite $\left(\mathrm{K}_{2} \mathrm{O} \cdot \mathrm{Fe}_{2} \mathrm{O}_{3} \cdot 4 \mathrm{SiO}_{2} \cdot 10 \mathrm{H}_{2} \mathrm{O}\right)$, limonite $\left(\mathrm{Fe}_{2} \mathrm{O}_{3} \cdot 3 \mathrm{H}_{2} \mathrm{O}\right)$, rutile $\left(\mathrm{TiO}_{2}\right)$, serpentine $\left(3 \mathrm{MgO} \cdot 2 \mathrm{SiO}_{2} \cdot 2 \mathrm{H}_{2} \mathrm{O}\right)$ and others [Valkov, V.F. et al., 2004, Chukhrov F.V. et al., 1970].

The sampling of waste was carried out in the territories of four construction sites from temporary storage sites (Figure 1).

Temporary storage sites are the sites with a concrete pavement and a curb along the perimeter (Figure 2). In the places of temporary storage, the waste is stored for no more than 2 days; afterwards it is transported to the landfill.

Sequence of actions for sampling involved:

1. Choosing 5-7 points, located evenly over the surface of the temporary dump.

2. The point samples weighing $2 \mathrm{~kg}$ were selected with a scoop.

Table 1. The volumes of rock formed during the development of underground objects (by years)

\begin{tabular}{|c|c|c|c|c|c|c|}
\hline \multirow{3}{*}{ Waste sources } & \multirow{2}{*}{$\begin{array}{l}\text { In just five } \\
\text { years }\end{array}$} & \multicolumn{5}{|c|}{ Years } \\
\hline & & 2012 & 2013 & 2014 & 2015 & 2016 \\
\hline & $\mathrm{m}^{3}$ & $\mathrm{~m}^{3}$ & $\mathrm{~m}^{3}$ & $\mathrm{~m}^{3}$ & $\mathrm{~m}^{3}$ & $\mathrm{~m}^{3}$ \\
\hline Mine shafts and near-barrels & 8710 & 1700 & 6120 & - & 890 & - \\
\hline Inclined (escalator) tunnels & - & - & - & - & - & - \\
\hline $\begin{array}{l}\text { Stations with station facilities. Dead } \\
\text { ends and move out tunnels. }\end{array}$ & - & - & - & - & - & - \\
\hline Subway tunnels and tunnel cameras & 378310 & & 43690 & 141200 & 177430 & 15980 \\
\hline $\begin{array}{l}\text { Subway tunnels, vestibules, upper } \\
\text { ventumblers, constructed by open } \\
\text { method }\end{array}$ & 174470 & 61070 & 61070 & 26170 & 26170 & - \\
\hline Total: & 561490 & 62760 & 110880 & 167370 & 204490 & 15980 \\
\hline
\end{tabular}




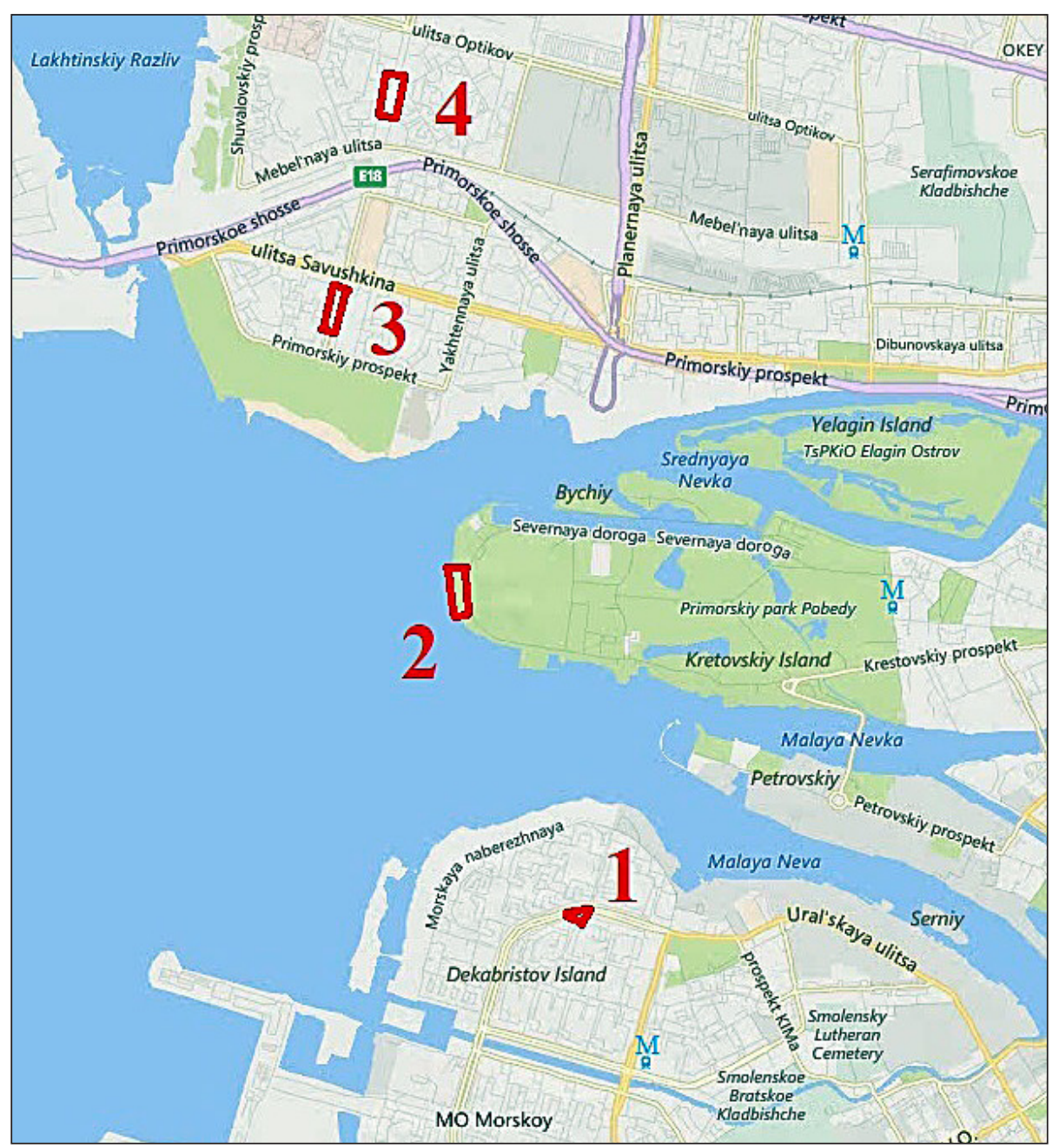

Figure 1. The layout of the construction sites of the subway: 1 - construction site of the mine \#467, 2 - station "Novokrestovskaya", 3 - station "Savushkina Street", 4 - mine \#462.

3. The point samples were combined on a clean flat section of the concrete platform to a mass of $5 \mathrm{~kg}$ combined sample.

4. The sample obtained was placed in a plastic bag.

Moisture was determined for the natural state and for air-dry conditions. The method of heating involves calculating the moisture content by weight of the water evaporated from a solid or liquid sample after heating for some time at a temperature equal to or higher than the evaporation temperature of the sample. The weight loss increases as the sample warms up and, in the end, tends to a constant value. The weight of the sample is $2 \mathrm{~g}$.

When determining the natural moisture of the waste, the sample was crushed to a uniform particle size with a diameter of less than $1 \mathrm{~mm}$, which provided a thorough heating and drying of each particle. The results of measuring the mois- ture content of samples in the natural state are presented in Table 2.

While determining the moisture of the waste in an air-dry state, the sample weights were predried. In order to do this, a sample of $100 \mathrm{~g}$ was selected from the initial sample, shredded with a spatula and evenly dispersed on kraft paper. The weighed portions were dried for 5 days and mixed daily for uniform drying. Then, the dried samples were crushed manually in porcelain mortars, after which the moisture content was determined. The results of measuring the moisture of samples in the air-dry state are presented in Table 3.

In order to determine the $\mathrm{pH}$, the pre-dried to air-dry state was weighed in a porcelain mortar, and the moisture was measured as described above. Afterwards, the sample was sieved through a sieve with a mesh size of $1-2 \mathrm{~mm}$. The resulting sample had a mass of $100-150 \mathrm{~g}$. Further, the conversion to dry matter was carried out according to the formula (1): 


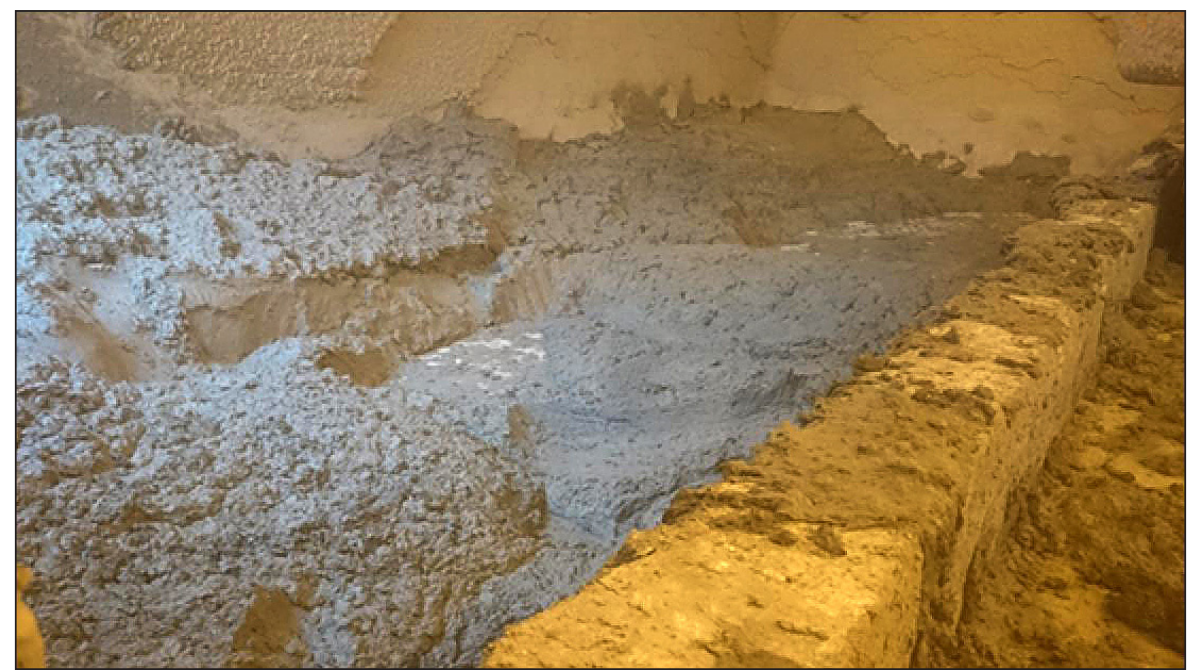

Figure 2. The site of temporary storage of rock on the mine site \#462

Table 2. The results of measuring the moisture of samples in the natural state

\begin{tabular}{|l|c|c|c|c|}
\hline \multicolumn{1}{|c|}{ Place of sampling } & $\begin{array}{c}\text { Station } \\
\text { "Savushkina Street" }\end{array}$ & $\begin{array}{c}\text { Station } \\
\text { "Novokrestovskaya" }\end{array}$ & Mine \#462 & Mine \#467 \\
\hline Moisture of sample, \% & 20.27 & 28.20 & 19.56 & 8.99 \\
\hline $\begin{array}{l}\text { Moisture of the } \\
\text { sample (parallel } \\
\text { measurement), } \%\end{array}$ & 20.35 & 27.90 & 19.51 & 9.02 \\
\hline Average value, \% & 20.31 & 28.05 & 19.53 & 9.00 \\
\hline
\end{tabular}

Table 3. Results of moisture measurement of samples in air-dry state

\begin{tabular}{|l|c|c|c|c|}
\hline \multicolumn{1}{|c|}{ Place of sampling } & $\begin{array}{c}\text { Station } \\
\text { "Savushkina Street" }\end{array}$ & $\begin{array}{c}\text { Station } \\
\text { "Novokrestovskaya" }\end{array}$ & Mine \#467 & Mine \#462 \\
\hline Moisture of sample, \% & 1.74 & 2.37 & 2.03 & 2.10 \\
\hline $\begin{array}{l}\text { Moisture of the } \\
\text { sample (parallel } \\
\text { measurement), } \%\end{array}$ & 1.77 & 2.31 & 2.20 & 2.15 \\
\hline Average value, \% & 1.75 & 2.34 & 2.11 & 2.12 \\
\hline
\end{tabular}

$$
\mathrm{M}_{\mathrm{ad}}=\mathrm{M}_{\mathrm{d}} /(1-\mathrm{P})
$$

where: $M_{a d}$ is the mass of the substance in the airdry state $(\mathrm{g})$,

$M_{d}$ is the mass in terms of dry matter $(\mathrm{g})$, $P$ is the moisture content in the air-dry state $(\%)$.

The sifted sample was rolled on a flat surface and portioned to obtain a sample weighing $30 \mathrm{~g}$ in terms of absolutely dry matter by the formula (1). The resulting sample was poured into a glass beaker, mixed with distilled water in a ratio of $1: 5$, stirred on a magnetic stirrer for 10 minutes, then left to stand for 5-10 minutes and the $\mathrm{pH}$ was measured.

The measurement was carried out using an ATP-02 automatic potentiometric titrator with a special attachment. The measurement results were displayed in the software interface of the device in the digital and graphical form.

The $\mathrm{pH}$ was determined on October 17, 2017. The air temperature in the room was $23^{\circ} \mathrm{C}$, the air humidity amounted to $32 \%$. On the basis of the results presented in Table 4 , it can be concluded that the waste in question is weakly acidic, and this property should be taken into account when developing the composition of the soil mixture.

Determination of the total carbon (TC) content was performed using a Shimadzu TOC device using the SSM-5000A solid-state assay attachment.

Principle of catalytic combustion method was as follows:

1. The analyzed sample is heated to $680^{\circ} \mathrm{C}$;

2 . As a result of combustion of organic substances of the sample, $\mathrm{CO}_{2}$ was obtained; 
Table 4. The results of determining the $\mathrm{pH}$ of the aqueous extract of waste

\begin{tabular}{|l|c|c|c|c|}
\hline \multicolumn{1}{|c|}{ Place of waste generation } & $\begin{array}{c}\text { Measurement result, } \\
\text { unit. } \mathrm{pH}\end{array}$ & $\begin{array}{c}\text { Result of parallel } \\
\text { measurement, unit. } \mathrm{pH}\end{array}$ & $\begin{array}{c}\text { Average value, } \\
\text { unit. } \mathrm{pH}\end{array}$ & $\mathrm{t},{ }^{\circ} \mathrm{C}$ \\
\hline Station "Novokrestovskaya" & 6.01 & 6.04 & 6.02 & 21 \\
\hline Station "Savushkina Street" & 5.53 & 5.50 & 5.51 & 21.5 \\
\hline Mine \#467 & 5.65 & 5.67 & 5.66 & 21 \\
\hline Mine \#462 & 5.91 & 5.92 & 5.91 & 21 \\
\hline
\end{tabular}

3. The combustion products are carried away from the reaction tube by a carrier gas stream;

4. The gas mixture enters the electronic dehumidifier, where it is cooled and freed from water vapor. Then, the gas passes through a halogen trap, in which chlorine and other halogens are absorbed;

5. A mixture of carrier gas and combustion products is fed to the IR detector, in which the measurement of $\mathrm{CO}_{2}$ absorption.

Sample preparation: drying to air-dry state, grinding in a porcelain mortar, determination of moisture.

The weight of the sample was $0.20 \mathrm{~g}$ in terms of dry matter according to formula (1). The weight of the sample was determined in accordance with the average carbon content in clay rocks $(0.5-3 \%)$ [Basic Scales... 1982, Valkov et al., 2004] and the corresponding calibration curve. The TC contents were measured in two parallel samples for each sample. The determination of the contents of the vehicle was carried out on October 18, 2017. The room temperature was $24^{\circ} \mathrm{C}$, air humidity $31 \%$. Eight measurements were made.

The results obtained indicate a low content of carbon and organic matter in the waste and correspond to the content of carbon in the main types of clays. The results are shown in Table 5 .

The chemical composition of the samples was studied using a XRF-1800 Shimadzu wave X-ray fluorescence spectrometer.

The method implemented in this device is based on the dependence of the intensity of X-ray fluorescence on the concentration of the element in the sample. When a powdered tablet of the sample is irradiated with a powerful radiation flux of the X-ray tube, characteristic fluorescent radiation of the atoms arises, which is proportional to their concentration in the sample.

Before the analysis, the sample was prepared as follows: drying to air-dry state, determination of moisture, grinding in a ball mill. A tablet is formed by means of the hydraulic press from the received powder. Afterwards, the tablet is placed in a special box of the spectrometer and an analysis is performed with a digital display of the results and plotting.

Calculation of the concentrations of elements is performed with standard software. When displaying the analysis results, the departing mineral composition consisting essentially of oxides of different elements is accounted for; therefore, the content of detectable conversion elements in oxide form has been set in the program.

During the analysis, the concentration of the already known total carbon and moisture of the sample was included in the instrument program for calculating the concentration.

The analysis was carried out on October 18 , 2017. The room temperature was $21^{\circ} \mathrm{C}$, whereas the air humidity equaled $32 \%$. The results are shown in Table 6.

The measurement results were determined with the standard software for the XRF-1800 and by the fundamental parameters method with a normalization of $100 \%$ of the content of the detected elements. Averaging over the surface of the sample was provided by rotating the sample at a speed of $50 \mathrm{rpm}$ during the recording of fluorescence radiation. The weight of the sample was $1 \mathrm{~g}$. The values of the signal with an intensity exceeding $1 / 3$ of the background value were taken into account.

Table 5. The content of total carbon in the waste

\begin{tabular}{|l|c|c|c|}
\hline \multicolumn{1}{|c|}{ Place of waste generation } & Measurement result, \% & $\begin{array}{c}\text { Result of parallel } \\
\text { measurement, \% }\end{array}$ & Average value, \% \\
\hline Station "Novokrestovskaya" & 0.72 & 0.74 & 0.73 \\
\hline Station "Savushkina Street" & 1.28 & 1.25 & 1.26 \\
\hline Mine \#467 & 1.21 & 1.23 & 1.22 \\
\hline Mine \#462 & 0.73 & 0.73 & 0.73 \\
\hline
\end{tabular}


Table 6. Content of chemical elements in the tested waste (\%)

\begin{tabular}{|c|c|c|c|c|}
\hline Substance & Station "Savushkina Street" & Station "Novokrestovskaya" & Mine \#462 & Mine \#467 \\
\hline $\mathrm{SiO}_{2}$ & 71.20 & 62.71 & 61.86 & 62.03 \\
\hline $\mathrm{Al}_{2} \mathrm{O}_{3}$ & 12.58 & 15.57 & 19.01 & 19.93 \\
\hline $\mathrm{K}_{2} \mathrm{O}$ & 3.78 & 4.05 & 4.71 & 4.82 \\
\hline $\mathrm{Fe}_{2} \mathrm{O}_{3}$ & 3.46 & 6.74 & 7.30 & 6.39 \\
\hline $\mathrm{CaO}$ & 2.30 & 3.20 & 0.67 & 0.20 \\
\hline $\mathrm{MgO}$ & 1.13 & 2.06 & 1.70 & 1.69 \\
\hline $\mathrm{TiO}_{2}$ & 0.70 & 0.95 & 1.13 & 1.13 \\
\hline $\mathrm{Na}_{2} \mathrm{O}$ & 0.66 & 0.73 & 0.14 & 0.08 \\
\hline $\mathrm{SO}_{3}$ & 0.53 & 0.16 & 0.17 & 0.08 \\
\hline $\mathrm{P}_{2} \mathrm{O}_{5}$ & 0.25 & 0.26 & 0.12 & 0.05 \\
\hline $\mathrm{BaO}$ & 0.16 & 0.15 & 0.14 & 0.12 \\
\hline $\mathrm{Cr}_{2} \mathrm{O}_{3}$ & 0.08 & 0.07 & 0.04 & 0.05 \\
\hline $\mathrm{MnO}$ & 0.07 & 0.12 & 0.11 & 0.03 \\
\hline $\mathrm{Nd}_{2} \mathrm{O}_{3}$ & 0.00 & 0.03 & 0.00 & 0.00 \\
\hline $\mathrm{ZrO}_{2}$ & 0.03 & 0.02 & 0.02 & 0.02 \\
\hline $\mathrm{SrO}$ & 0.03 & 0.03 & 0.01 & 0.01 \\
\hline $\mathrm{Cl}$ & 0.02 & 0.02 & 0.00 & 0.00 \\
\hline $\mathrm{Ga}_{2} \mathrm{O}_{3}$ & 0.00 & 0.02 & 0.00 & 0.00 \\
\hline $\mathrm{ZnO}$ & 0.01 & 0.01 & 0.02 & 0.02 \\
\hline $\mathrm{Rb}_{2} \mathrm{O}$ & 0.01 & 0.01 & 0.01 & 0.01 \\
\hline $\mathrm{Co}_{2} \mathrm{O}_{3}$ & 0.00 & 0.00 & 0.00 & 0.00 \\
\hline $\mathrm{NiO}$ & 0.00 & 0.01 & 0.01 & 0.01 \\
\hline $\mathrm{CuO}$ & 0.00 & 0.01 & 0.00 & 0.00 \\
\hline $\mathrm{C}$ & 1.26 & 0.73 & 0.73 & 1.22 \\
\hline Moisture & 1.75 & 2.34 & 2.12 & 2.11 \\
\hline
\end{tabular}

The granulometric analysis was carried out by laser diffraction using a laser particle size analyzer LA-950V2 Horiba. The principle of operation is based on scattering and detection of reflected / refracted laser light, red and blue spectra (650 and $405 \mathrm{~nm}$ ). Very thin particles of the submicron range scatter light from the LEDs at large angles. These signals are recorded on 4-channel detectors with increased sensitivity and a frequency of 5000 measurements per second.

The determination of the granulometric composition is necessary for further research. While choosing the composition of the soil mixture, the results of the analysis will allow us to name and classify this soil, and also to establish some agrophysical properties. The sample preparation con- sisted in drying the sample to an air-dry state and grinding it in a porcelain mortar. The analysis was conducted on 19.10.2017. The air temperature in the room was $21^{\circ} \mathrm{C}$, whereas the air humidity $32 \%$. On the basis of the results obtained, it can be concluded that the wastes under study are mainly composed of physical clay consisting of clay and dust particles. The results of the analysis are shown in Table 7.

The hazard class of waste was calculated in the following way: in accordance with the Order of the Ministry of Natural Resources and Ecology of the Russian Federation \#536 of December 4, 2014, the Methodological Handbook on the Application of Criteria for the Recognition of Hazardous Wastes to Hazardous Classes for

Table 7. Results of granulometric analysis of waste

\begin{tabular}{|l|c|c|c|}
\hline Place of waste generation & $\begin{array}{c}\text { Content of clay } \\
(\mathrm{d}<0.01 \mathrm{~mm}), \%\end{array}$ & $\begin{array}{c}\text { Content of sand } \\
(0.05<\mathrm{d}<1.0 \mathrm{~mm}), \%\end{array}$ & $\begin{array}{c}\text { The content of dust particles } \\
(0.001<\mathrm{d}<0.05 \mathrm{~mm}), \%\end{array}$ \\
\hline Station "Novokrestovskaya" & 74.0 & 5.5 & 88.5 \\
\hline Station "Savushkina Street" & 27.0 & 30.7 & 61.7 \\
\hline Mine \#467 & 72.7 & 2.5 & 91.6 \\
\hline Mine \#462 & 81.3 & 1.7 & 92.3 \\
\hline
\end{tabular}


the Environment], a literature review was first conducted aimed at studying the concentrations of oxygen, nitrogen, carbon, phosphorus, sulfur, silicon, aluminum, iron, sodium, potassium, calcium, magnesium, titanium in basic types of soils [Basic scales... 1982, Valkov et al., 2004]. Then, information was collected on 19 primary hazard indicators for those substances that do not belong to the rock-forming, or if their content in the waste exceeds the concentrations in the main types of soils. For this purpose, a literature review of reliable literature sources containing the confirmed information on hazard indicators was made [SanPiN 2.3.2.1078-01, Lazarev, 1976, Grushko, 1982] and a review of relevant state standards in place in Russia [GOST 17.4.1.02-83, GN 2.1.7.2042-06, GN 2.1.5.1315-03, GN 2.1.5.2307-07, GN 2.1.6.1338-03, GN 2.1.6.2309-07, SanPiN 2.1.7.1287-03, SP 2.1 .7.1386-03, MU 2.1.7.730-99].

After collecting all the necessary information, the calculation was carried out in the program "Integral. Calculation of hazard class 4.0". The concentrations of certain substances were recalculated from the percentage content in $\mathrm{mg} / \mathrm{kg}$. For this purpose, formula (2) was used:

$$
C_{i}=\frac{P_{i}}{100} * 1000000, \mathrm{mg} / \mathrm{kg}
$$

where: $C_{i}$ is the desired concentration of the i-th substance $(\mathrm{mg} / \mathrm{kg})$,

$P_{i}$ is the content of the $\mathrm{i}$-th substance in the sample (\%).

Further, the calculation of the content of atoms of certain elements from their oxide forms was calculated by formula (3):

$$
\mathrm{C}_{e i}=\frac{C_{i} * P_{e i}}{100}, \mathrm{mg} / \mathrm{kg}
$$

where: $C_{e i}$ is the concentration of the $\mathrm{i}$-th element in the sample $(\mathrm{mg} / \mathrm{kg})$,

$P_{e i}$ is the content of the atoms of the i-th element in the molecule of the i-th substance (\%) by the formula (4).

$$
P_{e i}=\frac{\mathrm{M}_{e}}{\mathrm{M}_{s}} * 100 \%, \%
$$

where: $M_{e}$ is the molecular mass of the element in the substance $(\mathrm{g} / \mathrm{mol})$,

$M_{s}$ is the molecular mass of the i-th substance $(\mathrm{g} / \mathrm{mol})$.
After the calculations, the obtained concentrations of oxygen, nitrogen, carbon, phosphorus, sulfur, silicon, aluminum, iron, sodium, potassium, calcium, magnesium and titanium were compared in the main soil types with concentrations of the corresponding substances in the waste samples. As a result, it was found that the content of all listed elements is within the permissible ranges; therefore, they are related to non-hazardous rock-forming elements.

For the rest of the substances, the hazard class was calculated in accordance with the procedure [Order of the Ministry... 2014]. As a result of calculations, it was found that all four samples of waste correspond to the 5 hazard class.

In order to determine the toxicity of the waste, a methodology was used to specify the toxicity of water from the change in the optical density of the Chlorella algae [PND F T 14.1: 2: 3: 4.10-2004]. Chlorella algae are often used for biotesting of sewage and solid waste [Radziemska et. al., 2017; Śliwka, 2014]. The technique is based on recording the differences in the optical density of the test culture of Chlorella algae grown on a medium containing no toxic substances (control sample) and test water samples with appropriate dilution, in which these substances may be present. The algae culture is grown on a $50 \%$ Tamia nutrient medium, the composition of which is presented in Table 8.

Solutions $\mathrm{A}$ and $\mathrm{B}$ are prepared separately: solution $\mathrm{A}\left(\mathrm{H}_{3} \mathrm{BO}_{3}-2.86 \mathrm{~g} / \mathrm{dm}^{3} ; \mathrm{MnCl}_{2} \times 4 \mathrm{H}_{2} \mathrm{O}\right.$ $\left.-1.81 \mathrm{~g} / \mathrm{dm}^{3} ; \mathrm{ZnSO}_{4} \times 5 \mathrm{H}_{2} \mathrm{O}-0.222 \mathrm{~g} / \mathrm{dm}^{3}\right)$ and solution $\mathrm{B}\left(\mathrm{MoO}_{3}-17.64 \mathrm{mg} / \mathrm{dm}^{3} ; \mathrm{NH}_{4} \mathrm{VO}_{3}\right.$, $22.96 \mathrm{mg} / \mathrm{dm}^{3}$, dissolved with heating).

Cultivation of algae was conducted in the KV-05 cultivator. A transparent bottle of colorless glass with a capacity of $400 \mathrm{~cm}^{3}$ was used as a reactor. Slurry of algae was poured into the reactor in a volume of $125 \pm 10 \mathrm{~cm} 3$. The container with the suspension continuously rotated about its longitudinal axis to provide carbon dioxide. In the process of cultivation, a constant medium temperature of $36.0 \pm 0.5^{\circ} \mathrm{C}$ was maintained.

Table 8. The composition of the nutrient medium Tamia for the cultivation of algae chlorella

\begin{tabular}{|l|c|}
\hline \multicolumn{1}{|c|}{ Component } & Concentration, $\mathrm{g}$ in $200 \mathrm{~cm}^{3}$ \\
\hline $\mathrm{KNO}_{3}$ & 20 \\
\hline $\mathrm{MgSO}_{4} \times 7 \mathrm{H}_{2} \mathrm{O}$ & 10 \\
\hline $\mathrm{KH}_{2} \mathrm{PO}_{4} \times 3 \mathrm{H}_{2} \mathrm{O}$ & 5 \\
\hline Iron citric acid & 0.6 \\
\hline Trace elements & Solutions A and B \\
\hline
\end{tabular}


Before biotesting, the algae culture was filtered and diluted to an optical density of $0.125 \pm 0.00550 \%$ by Tamia medium. The registration of the optical density of the culture of the test object was carried out using the density meter of the suspension IPS-03.

The sample preparation was carried out by drying a sample weighing $120-150$ g to an airdry state. The sample was neatly ground with a spatula, eliminating the particles larger than 10 $\mathrm{mm}$. Then, the sample were measured in $100 \mathrm{~g}$ in terms of dry matter and preparation of the extract of leaching was carried out afterwards. The resulting sample was poured into a glass beaker and $1000 \mathrm{ml}$ of distilled water was added. The resulting extract was stirred on a magnetic stirrer for 7-8 hours. After mixing, $100 \mathrm{ml}$ of the extract was purified from the suspensions by centrifugation for 10 minutes at $4000-4500 \mathrm{rpm}$. The resulting extract was ready for biotesting.

The water prepared in the biotesting in a volume of $50 \mathrm{~cm}^{3}$ was transferred to a glass beaker with a capacity of $100 \mathrm{~cm}^{3}$. In order to obtain a number of dilutions of the analyzed sample, divisible by three, $24 \mathrm{~cm}^{3}$ of distilled water was added in 24 cups. Afterwards, $12 \mathrm{~cm}^{3}$ of test water was introduced into the first of them, and in the second, third and fourth were carried by $12 \mathrm{~cm}^{3}$, from the first, second and third glasses, respectively. The $12 \mathrm{~cm}^{3}$ from the last glass is discarded. Along with the diluted test water, $24 \mathrm{~cm}^{3}$ of initial test water and $24 \mathrm{~cm}^{3}$ of control (distilled) water were added to separate beakers. Thus, we obtained the following six sample variants:

1. control sample, $0 \%$;

2. initial (not diluted) water sample, $100 \%$;

3. sample diluted 3 times, $33 \%$;

4. sample diluted 9 times, $11 \%$;

5. sample diluted 27 times, $3.7 \%$;

6. sample diluted 81 times, $1.2 \%$.

The prepared test-culture of algae was introduced in $1.5 \mathrm{~cm}^{3}$ into all 6 cups. At the same time, as a result of 17 -fold dilution of the planted culture, the content of the nutrients in the test water was required to ensure that the growth of algal cells would correspond to $0.6 \%$ Tamia medium, and the initial optical density of the alga test culture would be $0.030 \pm 0.002$. The contents of each glass were bottled in $5 \mathrm{~cm}^{3}$ in vial bottles (4 bottles for each variant of the tested water, including a control sample). The light exposure of samples was made in a KVM-05 multi-cultivator.
Under the same and controlled conditions, the device allows 24 samples to be simultaneously cultured at the temperature, light intensity, $\mathrm{CO}_{2}$ supply $(0.03 \%)$ and mixing. The exposure time was 1 hour. Afterwards, the fluorescence intensity parameters were measured; for this purpose, all cuvettes with the samples were placed in a cassette of the Foton-10 fluorimeter for 10-15 minutes. After starting the device, the values of the registered parameters were displayed in the interface of the "Foton 10" program.

Processing of results was as follows:

1 . The average value of optical density is calculated by the formula (5):

$$
D=\sum D_{i} / n_{i}
$$

where: $D$ is the average value of the optical density;

$D_{i}$ - the values of the optical density in the $i$-th parallel definition; $n$ is the number of parallel definitions.

2. The relative difference in the optical density for each dilution as compared to control (I) was calculated by formula (6):

$$
I=(D k-D o) / D k \times 100 \%,
$$

where: $D k$ and $D o$ are the average values of the optical density in the control and in the experiment, respectively.

3. The criterion for the toxicity of a water sample is a decrease in the average optical density in comparison with the control variant by $20 \%$ or more in case of inhibiting the growth of the test culture or increasing it by $30 \%$ or more when stimulating growth processes.

The quality of the tested water was determined on the basis of its toxicological characteristics through the amount of toxic dilution of water. This required dilution of a water sample that is divisible by three. The dilution for which the deviation index $I$ (calculated by formula (6)) exceeded the water toxicity criterion was selected.

The value of the toxic multiplicity of dilution $(T M D)$ of water and water extracts, if the criterion of toxicity in the form of a $20 \%$ growth suppression was exceeded, was calculated by the formula (7):

$$
T M D=10 \frac{\left(\log P_{l}-\log P_{S}\right) \times\left(I_{S}-0,2\right)}{I_{S}-I_{l}}+\log P_{S}
$$


If the criterion of toxicity in the form of $30 \%$ growth stimulation was exceeded, the calculation of TMD was carried out according to the formula (8):

$$
T M D=10 \frac{\left(\log P_{l}-\log P_{S}\right) \times\left(I_{s}-0,3\right)}{I_{S}-I_{l}}+\log P_{S}
$$

where: $P_{l}$ is the dilution value (large) at which the deviation index was below the toxicity criterion;

$P_{s}$ is the dilution value (smaller), at which the deviation index was higher than the toxicity criterion;

$I_{l}$ and $I_{s}$ are the values corresponding to these dilutions of the indices of the deviation in growth, expressed in fractions.

The date of water extract preparation was 21.10.2017. The biotesting was conducted on 22.10.2017 at room temperature $23^{\circ} \mathrm{C}$ and air humidity of $35 \%$.

The results of biotesting on the example of the water extract of the waste station "Novokrestovskaya" were presented in Table 9.

The calculations were made in accordance with the procedure [PND F T 14.1: 2: 3: 4.10-2004]. As a result of biotesting, it was found that all four wastes considered do not have a toxic effect at a multiplication factor of $\mathrm{k}=1$. This confirms the safety of the waste and the hazard class established by the calculation method.

\section{CONCLUSION}

A complex analysis of the waste generated at the subway construction sites was carried out. The purpose of this analysis was to determine the possibility of using waste in the urban economy, in particular, as a component of the soil mixture.

The chemical composition of the samples was established that they comprised $\mathrm{SiO}_{2}$ (from $62.71 \%$ to $71.20 \%$ ), $\mathrm{Al}_{2} \mathrm{O}_{3}$ (from $12.58 \%$ to $15.57 \%$ ), $\mathrm{K}_{2} \mathrm{O}$ (from $3.78 \%$ to $4.05 \%$ ), $\mathrm{Fe}_{2} \mathrm{O}_{3}$ (from $3.46 \%$ to $6.74 \%$ ), $\mathrm{CaO}$ (from $2.30 \%$ to $3.20 \%$ ), and $\mathrm{MgO}$ (from $1.13 \%$ to $2.06 \%$ ).

The determination of the granulometric composition is necessary for further research. While choosing the composition of the soil mixture, the results of the analysis will allow us to name and classify this soil, and also to establish agrophysical properties. As a result of calculations, it was found that all four samples of waste correspond to the $5^{\text {th }}$ class of danger.

The technique to determine the toxicity of water was based on recording the differences in the optical density of the test culture of Chlorella algae grown on a medium containing no toxic substances (control sample) and test water samples with appropriate dilution, in which these substances may be present. As a result of biotesting, it was found that all four wastes considered do not have a toxic effect at a multiplication fac-

Table 9. The result of biotesting as an example of waste from station "Novokrestovskaya"

\begin{tabular}{|c|c|c|c|c|c|c|}
\hline \# Sample & $\begin{array}{l}\text { Multiplicity of } \\
\text { dilution }\end{array}$ & \# Replicates & $x$ & $\mathrm{X}_{\mathrm{a}}$ & $I, \%$ & $\begin{array}{c}\text { Have (does not have) acute } \\
\text { toxic effect }\end{array}$ \\
\hline Control & 0 & $\begin{array}{l}1 \\
2 \\
3 \\
4\end{array}$ & $\begin{array}{l}4.663 \\
4.634 \\
4.545 \\
4.560\end{array}$ & 4.603 & 0 & - \\
\hline 1 & 1 & $\begin{array}{l}1 \\
2 \\
3 \\
4\end{array}$ & $\begin{array}{l}4.485 \\
4.675 \\
4.632 \\
4.935\end{array}$ & 4.681 & $-1.70 \%$ & Not have \\
\hline 2 & 3 & $\begin{array}{l}1 \\
2 \\
3 \\
4\end{array}$ & $\begin{array}{l}4.582 \\
4.669 \\
4.662 \\
4.771\end{array}$ & 4.671 & +-1.49 & Not have \\
\hline 3 & 9 & $\begin{array}{l}1 \\
2 \\
3 \\
4 \\
\end{array}$ & $\begin{array}{l}4.571 \\
4.560 \\
4.535 \\
4.528 \\
\end{array}$ & 4.548 & +1.18 & Not have \\
\hline 4 & 27 & $\begin{array}{l}1 \\
2 \\
3 \\
4\end{array}$ & $\begin{array}{l}4.651 \\
4.594 \\
4.699 \\
4.787\end{array}$ & 4.683 & $-1.74 \%$ & Not have \\
\hline 5 & 81 & $\begin{array}{l}1 \\
2 \\
3 \\
4\end{array}$ & $\begin{array}{l}4.796 \\
4.774 \\
4.870 \\
4.675\end{array}$ & 4.772 & $-3.68 \%$ & Not have \\
\hline
\end{tabular}


tor of $k=1$. This confirms the safety of the waste and the hazard class established by the calculation method.

\section{Acknowledgements}

This scientific work was supported by the Government of Saint-Petersburg, a grant from the President of the Russian Federation and the Center for Collective Use of the Saint-Petersburg Mining University.

\section{REFERENCES}

1. Basic scales of properties of morphological elements of soils. VASKhNIL Publishing. Dokuchaev Soil Institute, Moscow 1982, pp. 55.

2. Chukhrov, F.V. Petrov, V.P., Nikitina, A.P. 1970. Clays, their mineralogy, properties and practical significance: Collection of articles. Academy of Sciences of the USSR, Institute of Geology of Ore Deposits, Petrography, Mineralogy and Geochemistry. Moscow: Science. 271 p.

3. Danilov, A., Smirnov, Y., Korelskiy, D. 2017. Effective methods for reclamation of area sources of dust emission. Journal of Ecological Engineering, 18(5), 1-7

4. GN 2.1.5.1315-03.Maximum permissible concentration (MPC) of chemical substances in water of water bodies of economic, drinking and culturalhousehold water use.

5. GN 2.1.5.2307-07.Approximate permissible levels (ODUs) of chemicals in water in water bodies for domestic and drinking and cultural and domestic water use.

6. GN 2.1.6.1338-03.Maximum permissible concentration (MPC) of pollutants in the atmospheric air of populated areas.

7. GN 2.1.6.2309-07.Indicative Safe Levels of Exposure (ISLE) of Pollutants in the Atmospheric Air of Populated Areas.

8. GN 2.1.7.2042-06.Approximate permissible concentrations (APC) of chemical substances in soil.

9. GOST 17.4.1.02-83.Protection of nature.Soil. Classification of chemicals for pollution control.

10. GOST 5180-84. Soils.Methods for laboratory determination of physical characteristics.

11. GOST 26423-85.Soils.Methods for determination of specific electric conductivity, $\mathrm{pH}$ and dense residue of aqueous extract.

12. GOST R 8.777-2011. State system for ensuring the uniformity of measurements (ICG). Disperse composition of aerosols and suspensions. Determination of particle size by diffraction of laser radiation. ISO 13320-1: 1999 Granulometric analysis. Methods of laser diffraction.Part 1.General principles.

13. Grushko, Ya.M. 1982. Harmful organic compounds in industrial wastewater. Leningrad: Chemistry, pp. 161.

14. Lazarev, N.V. 1976. Harmful substances in industry.A reference book for chemists, engineers and doctors. In 3 volumes. Leningrad: Chemistry, pp. 608 .

15. Methodical manual on the application of "Criteria for classifying hazardous wastes as hazard classes for the environment". Ministry of Natural Resources of the Russian Federation. Moscow 2003, pp. 38.

16. MU 2.1.7.730-99.Hygienic assessment of soil quality in populated areas.

17. Order of the Ministry of Natural Resources and Ecology of the Russian Federation of December 4, 2014 \#536. On the Approval of Criteria for classifying wastes as hazard class IV according to the degree of negative impact on the environment. http: //docs.cntd. com / document / 420240163

18. Pashkevich, M.A. 2015. Environmentally safe methods of technogenic deposits conservation. Notes of the Mining Institute. National Mineral Resources University "University of Mines" in Saint-Petersburg, Vol. 213, 86-93.

19. PND F 12.1: 2: 2.2: 2.3: 3.2-03. Methodical recommendations.Sampling of production and consumption wastes.

20. PND F T 14.1: 2: 3: 4.10-2004. Toxicological methods of analysis. Method for determining the toxicity of drinking, natural and waste water, water extracts from soils, sewage sludge and production and consumption wastes by changing the optical density of chlorella alga.

21. Radziemska, M., Mazur, Z. 2017. Chemical composition of spring rapeseed grown in copper contaminated soil amended with halloysite and Zeolite. Journal of Ecological Engineering, 18(2), 38-43

22. SanPiN 2.1.7.1287-03.Sanitary and epidemiological requirements to soil quality.

23. SanPiN 2.3.2.1078-01.Hygienic requirements for safety and nutritional value of food products.

24. SP 2.1.7.1386-03. Sanitary rules for determining the hazard class of toxic production and consumption wastes.

25. Valkov, V.F. Kazeev, K.Sh. Kolesnikov, S.I. 2004. Soil Science: Textbook for high schools.: Publishing Center "Mart". Moscow, pp. 496. 